\title{
...VERA FIDELIUM RELATIO... COSMAS ANGABEN ÜBER DIE ANFÄNGE DER „HISTORISCHEN“ PERIODE DER BÖHMISCHEN GESCHICHTE
}

\author{
MARIE BLÁHOVÁ \\ Philosophische Fakultät, Karls-Universität, Prag \\ E-mail: marie.blahova@ff.cuni.cz
}

\begin{abstract}
... vera fidelium relatio ...: The Cosmas's information on the Beginnings of the "Historical" Period of the Czech History

The author deals with the sources that the oldest Czech chronicler, the Dean of the Prague Chapter Cosmas $(\dagger 1125)$ used for his interpretation of older Czech history and the personality of the third Prague bishop Thiddag (998-1017). On the basis of an analysis of Cosmas's text, the author concluded that the chronicler had, in addition to the Imperial annals, a catalogue of Prague bishops, incomplete reports of the succession of Czech rulers, several annalistic records of Czech history, and an oral tradition. The lack of information in some places was replaced by his rhetorical abilities. As for Bishop Thiddag, Cosmas tells about his election and enthronement, then about his death on June 11, 1017. It is apparent that Cosmas did not know much about the third bishop of Prague and the events that took place under his office, so he helped out the usual rhetorical topoi.
\end{abstract}

Keywords: Cosmas's Chronicle; sources; Bohemia; Thiddag

„Im Jahre des Herrn 998. Am 7. Juli wurde Thiddag geweiht und ehrerbietig von der Geistlichkeit und dem Volk der Prager Kirche und in großer Freude auf den Bischofsthron an der Ecke des Altars von Sankt Veit gesetzt"1. Mit diesen Worten beschrieb der erste böhmische Historiker, der Dekan des Prager Bischofskapitels Cosmas († 1125) die Amtseinführung des dritten Prager Bischofs. Cosmas schrieb sein Werk mehr als einhundert Jahre später, in der zweiten Hälfte des zweiten Jahrzehnts des 12. Jahrhunderts $^{2}$. In diesem Zusammenhang müssen wir uns die Fragen stellen, woher Cosmas die Informationen über jene Ereignisse schöpfen konnte, die sich zur Wende des 10. und 11. Jahrhunderts abspielten, und welchen Charakter diese Angaben besaßen, beziehungsweise in welchem Maß sie „zuverlässig“ sind. Im Voraus sei darauf hingewiesen: obwohl Cosmas erhebliche Betonung auf seine Ausdrucksart legte, sich nach den rhetorischen Regeln richtete und rhetorische Mittel anwandte, so ist es nicht anzunehmen, auch wenn man das intertextuelle Studium in bestimmten Zusammenhängen als sehr nutzbringend ansieht, dass Cosmas sein Werk nur oder vor allem deshalb geschrieben habe, um sei-

1 Cosmae Pragensis Chronica Boemorum (MGH Scriptores Rerum Germanicarum. Nova series. Bd. 2), hg. von Bertold BRETHOLZ. Berlin 1923, S. 56 (I 31).

2 Vgl. Dušan TǨEŠTÍK, Kosmova kronika: studie k počátkům českého dějepisectví a politického myšlení. Praha 1968, S. 50-54. 
nen Kollegen die eigene Redegewandtheit vorzuführen, wie dies heute fast zur Mode geworden ist ${ }^{3}$, sondern vor allem deshalb, weil er seinen Lesern oder Zuhörern etwas Konkretes mitteilen wollte ${ }^{4}$.

Seine Quellen gibt der Chronist selbst an: die älteste Periode der böhmischen Geschichte, also die „mythische Geschichte“, schildert Cosmas angeblich nach der „sagenhaften Überlieferung der Alten“5. Hier werden nicht die Fragen behandelt, was Cosmas wirklich von den „Alten“ gehört und was er selbst, häufig unter dem Einfluss der antiken Literatur ${ }^{6}$, erdichtet hat. In Zusammenhang mit dem dritten Prager Bischof werden die Quellen von Cosmas Informationen für die nächste von ihm beschriebene Periode untersucht, also - nach Cosmas - „die denkwürdigen Dinge, die durch eine glaubwürdige Wiedergabe verbürgt sind"7.

Das erste durch eine „glaubwürdige Wiedergabe“ verbürgte Ereignis ist der Bericht über die Taufe von Fürst Bořivoj im Jahr $894^{8}$. Einige Kapitel früher, also im nach der „sagenhaften Überlieferung der Alten“ geschriebenen Teil, konnte der Leser erfahren, dass Bořivoj getauft wurde „vom ehrenhaften Method, dem Bischof von Mähren, zu Zeiten des Kaisers Arnolf und des mährischen Königs Svatopluk “9. Wenn diese Information der Wahrheit entspräche und das Taufdatum bei Cosmas richtig wäre, hätte Method den Bořivoj neun Jahre nach dem eigenen Tod am 6. April 885 und ganz am Lebensende des Königs Svatopluk getauft, oder eher auch nach dessen Tod $(† 894)$. - Hier muss wohl Lisa Wolverton zugestimmt werden, dass Cosmas in seiner Vorlage, der Chronik des Abts Regino von Prüm, das Todesdatum von Svatopluk im Jahr 894 gefunden hat und als einziges Datum, das ihm für Svatopluks Regierungszeit zur Verfügung stand, verwendete er als Bořivojs Taufdatum ${ }^{10}$. Dieses Datum entspricht außerdem der Angabe „zu Zeiten des Kaisers Arnolf“ (Arnolf von Kärnten, ab 887 König des Ostfrankenreichs, starb am 8. Dezember 899). Wenn Cosmas Datum von Bořivojs Taufe „durch glaubwürdige Wiedergabe" verbürgt sein sollte, dann konnte jedoch Methods Teilnahme an der Taufe nicht gelten.

3 Beispielsweise Lisa WOLVERTON, Cosmas of Prague: Narrative, Classicism, Politics. Washington D.C. 2015.

${ }^{4}$ Dieses Verfahren ist zutreffend von Georg Scheibelreiter charakterisiert: „Während manche Fachkollegen viel Mühe aufwenden, unter dem Schlagwort der Intertextualität die letzte Wirklichkeit aus Annalen und Chroniken, Historien und Gesta zu vertreiben, wird diese zum bloßen Erzeugnisse intellektuellen Kommunikation erklären..." Vgl. Georg SCHEIBELREITER, Der Tod Lamberts von Maastricht, in: Natalie Fryde - Dick Reitz (Hgg.), Bischofsmord im Mittelalter: Murder of Bishops. Göttingen 2003, S. 51 f. und auch Hans-Werner GOETZ, Geschichtsschreibung und Geschichtsbewußtsein im hohen Mittelalter. Berlin 1999, S. 133 f.

5 „... senum fabulosa relatione...“ Die Chronik der Böhmen, S. 3 (I Item ad Gervasium magistrum prefacio)

6 Antonín KOLÁR̆, Kosmovy vztahy k antice, in: Sborník filosofické fakulty University Komenského $v$ Bratislavě 3/28 (1925), S. 21-99; Miloslav ŠVÁB, Latinské předkarlovské kroniky a listy Jindřicha z Isernie ve vztahu k antice, in: Ladislav Varcl (Hg.), Antika a česká kultura. Praha 1978, S. 34-41.

7 „... ea que vera fidelium relatio commendat... ad exarandum digna memorie se acuat." Die Chronik der Böhmen, s. 32 (I 13).

8 „Anno dominice incarnationis DCCCLXXXXIIII Borivoy baptizatus est primus dux sancte fidei catholicus." Die Chronik der Böhmen, S. 32 (I 14).

9 „Gostivit autem genuit Boriwoy, qui primus dux baptizatus est a venerabili Metudio episcopo in Moravia sub temporibus Arnolfi imperatoris et Zuatopluk eiusdem Moravie regis." Vgl. Die Chronik der Böhmen, S. 22 (I 10).

10 WOLVERTON, Cosmas of Prague, S. 56-60. 
Im ersten Teil der „historischen Periode“ der Cosmas-Chronik, konkret in der Zeit von Bořivojs Taufe bis zum Ende des ersten Buchs der Chronik, also bis zur Festigung der Regierung von Fürst Břetislav (1034-1055) in den dreißiger Jahren des 11. Jahrhunderts, sind wenigstens mitunter konkrete Daten der historischen Ereignisse angegeben, die Ereignisse machen einen zuverlässigeren Eindruck und einige lassen sich durch andere Quellen oder spätere Vorkommnisse überprüfen. Erst danach, also ab den dreißiger Jahren des 11. Jahrhunderts, beginnen die Ausführungen darüber, „was wir selbst gesehen oder was wir aus der glaubwürdigen Erzählung von Augenzeugen gehört haben“11.

Lassen wir den Umstand beiseite, dass Cosmas auch diese Zeit nicht vollständig aus eigener Erfahrung schildern konnte und dass sich an die Ereignisse der dreißiger Jahren des 11. Jahrhunderts nur sehr wenige Zeitgenossen von Cosmas erinnern konnten, und wenden wir unsere Aufmerksamkeit dem zweiten Teil des ersten Buchs von Cosmas Chronik $\mathrm{zu}$, also der Zeit von Bořivojs (angeblicher) Taufe bis zum Regierungsantritt Břetislavs I. (894-1038). An die Ereignisse dieses Zeitraums erinnerte sich Cosmas selbstverständlich nicht, aber auch nicht seine um eine Generation älteren Kollegen. Die Berichte konnte er also nicht von glaubwürdigen Zeugen erhalten haben, wie er behauptet. Ihm mussten auch schriftliche Quellen zur Verfügung stehen, die ihm genaue Daten und Informationen über die Ereignisse vermittelten. Dušan Třeštík sah als Quelle der Informationen von Cosmas für die ältere Zeit Annalen an, deren Führung er bei der bischöflichen Kirche seit Ende des 10. Jahrhunderts annahm, später sollen sie jedoch überarbeitet und erweitert worden sein ${ }^{12}$. Dem stimmt Lisa Wolverton nicht zu und nimmt an, dass Cosmas seine Erzählungen selbst aus Fragmenten zahlreicher Texte zusammenstellte ${ }^{13}$.

Zur Bestimmung des Typs der Quellen des Chronisten könnten wahrscheinlich der Charakter seiner Informationen und die Formulierungen der Chronik zu den einzelnen Ereignissen beitragen. Im erwähnten zweiten Teil des ersten Buchs der Cosmas-Chronik, der nicht ganz 50 Druckseiten der kritischen Edition darstellt, wechseln sich kurze annalistische Einträge mit Jahresdaten und detaillierten Schilderungen über einige Personen, Ereignisse und Institutionen ab, mitunter undatiert, manchmal mit Jahresangaben, mitunter auch mit Tagesdaten. Soweit aus dem erhaltenen Text der Chronik geurteilt werden kann, ging Cosmas offenbar ähnlich vor, wie die Verfasser älterer Annalen: er trug zunächst in das Arbeitsexemplar der Handschrift seiner Chronik die Jahreszahlen ein und fügte ihnen dann die Ereignisse hinzu, die er aus seinen Quellen auswählte ${ }^{14}$. Nicht immer fand er jedoch einen aufzeichnungswerten Stoff, so dass eine Reihe von Jahreszahlen leer blieb.

Wie hier bereits festgestellt wurde, beginnt der zweite Teil des ersten Buchs der Cosmas-Chronik mit dem Bericht über Bořivojs Taufe und der Darlegung über den Tod des

11 Die Chronik der Böhmen, S. 80 (I 42).

12 Vgl. TŘEŠTÍK, Kosmova kronika, S. 60 f.; DERS., Anfänge der böhmischen Geschichtsschreibung: die ältesten Prager Annalen, in: Studia Źródłoznawcze. Commentationes 23 (1978), S. 1-37; DERS., Počátky Přemyslovcui: vstup Čechů do dějin (530-935). Praha 1997, S. 102-110.

13 WOLVERTON, Cosmas of Prague, S. 39 f.

14 Vgl. Wesley M. STEVENS, Ars computi quomodo inventa est, in: Richard Conradini - Max Diesenberger - Meta Niederkorn-Bruck (Hgg.), Zwischen Niederschrift und Wiederschrift: Hagiographie und Historiographie im Spannungsfeld von Kompendienüberlieferung und Editionstechnik. Wien 2010, S. 69; Rosamond McKITTERICK, Entstehung und Gestaltung fränkischer Annalen im Spiegel der Lorscher Annalen, in: Ebd., S. 104-114. 
mährischen Königs Svatopluk mit einem kurzen Eintrag über seine Nachfolger. Alles ist unter dem erwähnten Jahr 894 angegeben ${ }^{15}$. Es folgt ein kurzer undatierter Bericht über Bořivojs Söhne und seine Ehefrau, über Bořivojs Tod, die Regierung seines Sohns Vratislav, dessen Gattin und Söhne ${ }^{16}$. Was die Einzelheiten zu diesen Personen betrifft, so verweist Cosmas auf andere, den Lesern offenbar bekannte Schilderungen, nämlich das Privilegium der mährischen Kirche, den Epilog Mährens und Böhmens sowie die Vita des heiligen Wenzel ${ }^{17}$. Aus diesen oft und immer noch ohne klares Ergebnis diskutierten Quellen hat Cosmas jedoch seinen eigenen Worten zufolge nicht geschöpft.

Die Jahreszahlen 895-928 blieben unbesetzt, obwohl den Ereignissen dieses Zeitraums ein ganzes Kapitel vorbehalten wurde ${ }^{18}$. Dem Jahr 929 ordnete Cosmas seine Berichte über die Ermordung des Fürsten Wenzel, über die Geburt von Boleslav I. Sohn Strachkvas ${ }^{19}$ und dessen Eintritt in das Kloster Sankt Emmeram in Regensburg $\mathrm{zu}^{20}$.

Über die Taten des Fürsten Boleslav (I.) konnte Cosmas angeblich nichts Aufzeichnungswertes erfassen, außer dem Bericht über die Weihe der Kirche, die von seinem Bruder errichtet und die bislang noch nicht eingeweiht worden war ${ }^{21}$. Nach zwei kurzen annalistischen Einträgen zu den Jahren 930 und 931, die aus der Fortsetzung der Chronik Reginos übernommen wurden ${ }^{22}$, folgt ein Bericht über die Überführung der sterblichen Überreste des heiligen Wenzels nach Prag und eine detaillierte Schilderung der „unmenschlichen Tat“, die der zukünftige Brudermörder Boleslav „der Grausame“ beim Bau der Burg Stará Boleslav begangen hatte ${ }^{23}$. Diese Schilderung sollte offenbar den gottlosen und erbarmungslosen, ja grausamen Charakter des Fürsten dokumentieren. Es folgen eine Serie kurzer analistischer Einträge für die Jahre 933-951, die wiederum aus der Fortsetzung der Chronik Reginos übernommen wurden, sowie fünfzehn „leere“ Jahreszahlen (952-966) ${ }^{24}$. Unter dem Jahr 967 ist ein Bericht über den Tod Boleslavs „des Grausamen" und den Antritt seines gleichnamigen, aber frommen Sohnes auf den Thron angegeben ${ }^{25}$. Als bedeutendste Tat Boleslavs II. wird eine Darlegung über die Gründung des Bistums Prag und des Georgsklosters angeführt, die mit einer fiktiven päpstlichen Urkunde dokumentiert wird ${ }^{26}$. Das Tendenzielle dieser Berichterstattung, in der Cosmas die vorbereitenden Verhandlungen Boleslavs I. völlig verschweigt und die Gründung des Bistums allein seinem Sohn zuschreibt, ist allgemein bekannt ${ }^{27}$.

Das nächste Kapitel ist der Persönlichkeit, der Wahl und feierlichen Amtseinführung des ersten Prager Bischofs Thietmar gewidmet, einschließlich des Wortlauts eines Schreibens, mit dem Boleslav II. Kaiser Otto II. um die Weihe des neuen Bischofs ersucht haben

15 Die Chronik der Böhmen, S. 32 f. (I 14).

16 Ebd, S. 34 f. (I 15).

17 Ebd., S. 35 (I 15). Vgl. dazu TřEŠTÍK, Kosmova kronika, S. 54 ff.

18 Die Chronik der Böhmen, S. 35 (I 16).

19 Ebd., S. 35 f. (I 17).

20 Ebd., S. 36 f. (I 18).

21 Ebd., S. 37 f. (I 18).

22 Ebd., S. 38. (I 19).

23 Ebd., S. 38 f. (I 19).

${ }^{24}$ Ebd., S. 40 f. (I 20).

25 Ebd., S. 41 f. (I 20).

26 Die Chronik der Böhmen, S. 42-44 (I 22). Zu dieser Urkunde vgl. Ivan HLAVÁČEK, Die Formung der westslawischen Schrift-, Buch- und Bibliothekskultur unter dem Einfluß der lateinischen Kirche, in: Gli Slavi occidentali e meridionali nell' alto medioevo 30 (1983), S. 84 f.

27 Vgl. TŘEŠTíK, Kosmova kronika, S. 61 f. 
soll, und der Beschreibung von Thietmars Thronbesteigung in der Prager Kirche, die nun Bischofskirche war ${ }^{28}$. Das Kapitel endet mit einem kurzgefassten Bericht über den Tod des heute nicht näher bekannten Großen Vok im Jahr $968^{29}$. Im folgenden Kapitel erstattet Cosmas Bericht über die einzigen konkreten Tätigkeiten des ersten Prager Bischofs aus seiner kurzen Amtszeit, von der Cosmas erfahren hat, und die den Bischof sicher sehr beschäftigte, nämlich die Einweihung der bereits längere Zeit errichteten und noch uneingeweihten Kirchen, die die Gläubigen zur Preisung Gottes in Böhmen erbaut hatten, und das Taufen des zahlreichen "heidnischen“ Volkes. Cosmas verband diese Angaben mit dem Bericht über Thietmars Tod am 2. Januar $969^{30}$.

Es folgt eine eingehende Schilderung über die Rückkehr des Slavnikiden Adalbert/ Vojtěch aus dem Studium in Magdeburg und über seine Wahl zum Prager Bischof am 19. Februar 968, mit fiktiven Ansprachen und einer schillernden Beschreibung seiner $W_{a h l}{ }^{31}$, ferner über Adalberts Investitur am 3. Juni und über seine Weihe am 11. Juni 968 in Verona. Dann schildert Cosmas Adalberts festliche Aufnahme in Prag mit der Beschenkung des Bistums durch Boleslav II. auf Rat von Bischof Adalbert und Fürsprache von Boleslavs Schwester, Äbtissin von Sankt Georg Kloster auf der Prager Burg, Maria ${ }^{32}$.

Es folgen wiederum nur kurzgefasste Berichte zu einigen Jahren: Über die Jahre 970 und 971 ist kein Bericht vermerkt. Im Jahr 972 starb der hl. Ulrich ${ }^{33}$, unter dem Jahr 977 folgt Bericht über den Tod der Přemyslidin Doubravka mit einer leicht entehrenden Anmerkung an die Adresse der Fürstin ${ }^{34}$. Die folgende Mitteilung, die den Tod Slavníks, des Vaters des heiligen Adalberts, konstatiert, mit genaueren Angaben im Nekrolog, bezieht sich erst auf das Jahr $981^{35}$. Die Zeilen mit den Jahreszahlen 982 und 983 sind leer ${ }^{36}$. Von Wichtigkeit im Bericht über den Tod von Kaiser Otto II. 984 sind dessen freundschaftliche Beziehung und die Beschenkung des Prager Bischofs Adalbert mit Gewändern, die „bis heute als Kleinode in der Prager Kirche aufbewahrt werden und Gewänder des

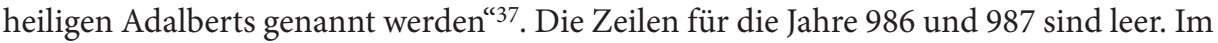
Jahr 987 starb dann der Chronik zufolge Střezislava, die Mutter des heiligen Adalberts ${ }^{38}$. Die nachfolgenden Jahreszahlen bis 994, mit Ausnahme des Jahres 990, als der Chronik folgend der heilige Adalbert in das Kloster St. Alexius in Rom eintrat, sind wieder ereignislos ${ }^{39}$. Es folgt eine eingehende Schilderung über die Gründe, die Adalbert zum Verlassen Böhmens bewegten und die den Bericht über den Tod von Adalberts Brüdern

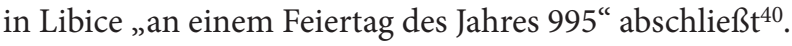

28 Die Chronik der Böhmen, S. 44 ff. (I 23).

29 Ebd., S. 46 (I 23).

30 Ebd., S. 46 (I 24).

31 Ebd., S. 46 f. (I 25).

32 Ebd., S. 47 f. (I 26).

33 Ebd., S. 48 (I 27).

34 Die Chronik der Böhmen, S. 49 (I 27).

35 Ebd., S. 49 f. (I 27).

36 Ebd., S. 50 (I 28).

$37, \ldots$ Insuper dat ei paramenta, in quibus missam celebrarat in pascha, scilicet albam, dalmaticam, casulam, cappam et faciterium, quo ea habeat sui ob memoriam. Que usque hodie in Pragensi ecclesia honorifice habentur et dicuntur paramenta sancti Adalberti." Ebd., S. 50 f. (I 28).

38 Ebd., S. 51 (I 28).

39 Ebd., S. 51 (I 28).

40 Ebd., S. 52 f. (I 29). 
Die Schilderung der Verhandlungen von Fürst Boleslav mit dem Mainzer Erzbischof über die Rückkehr des Bischofs Adalbert nach Böhmen oder über die Erlaubnis, einen anderen Bischof zu weihen, ist verflochten mit fiktiven Aussprüchen des Fürsten und des Papstes, der sich bemühte, Adalbert zur Heimkehr zu bewegen. Nähere Informationen soll wiederum die Vita des hl. Adalbert enthalten, denn Cosmas erscheint es nicht als angebracht, bereits Gesagtes zweimal zu erzählen ${ }^{41}$. Fast ungerecht scharf verurteilt er dann den Přemysliden Strachkvas, der schließlich gegen den eigenen Willen seiner Wahl und Weihe zum Prager Bischof zustimmte ${ }^{42}$.

Der Bericht über Adalberts Tod im Land der Prußen am Freitag, dem 23. April, Cosmas zufolge 996 anstatt 997, ist sehr gerafft ${ }^{43}$. Detaillierter ist die Schilderung von Boleslavs Verhandlungen über einen neuen Bischof mit Otto III. im Jahr 997. Die Wahl fiel auf den Kaplan des Königs Thiddag ${ }^{44}$.

Im Einzelnen geschildert wird wieder Boleslav II. und dessen Tod mit der vorhergehenden Belehrung seines Sohns ${ }^{45}$ - dies sind jedoch eher Cosmas Ansichten und seine Ratschläge für die zeitgenössischen Fürsten als authentische Lehren für Boleslav III. Nach dem Bericht über den Tod von Adalberts Bruder, dem Bischof von Gniezno Radim/ Gaudentius $^{46}$, werden kurz die Verdienste Boleslavs II. um die Ausdehnung der Grenzen des böhmischen Fürstentums mit einem Verweis auf die päpstliche Bestätigung des Prager Bistums genannt ${ }^{47}$. Es folgt eine Beschreibung der unrühmlichen Regierung von Boleslav III., seiner Verstümmelung und Gefangenschaft in Polen, und der groben Behandlung des „Fürstensohns“ Jaromír in Zbečno durch die Vršovci ${ }^{48}$. Cosmas präsentiert Boleslavs III. Brüder Jaromír und Oldřich als dessen Söhne. Die Chronik setzt fort mit einem Bericht über die Besetzung der Prager Burg durch den polnischen Fürsten Mieszko - richtig jedoch durch Bolesław („den Tapferen“) - in den Jahren 1000 und 1001, sowie Mieszkos Intervention beim römischen Kaiser gegen den Bruder (im Cosmas Darstellung gegen den Sohn) von Boleslav III., Oldřich ${ }^{49}$.

Mit einigen Details wiederum wird die Vertreibung der Polen aus Prag mit Hilfe des heiligen Wenzels im Jahr 1002 beschrieben und kurz ist Oldřichs Rückkehr und Blendung seines Bruders Jaromír beschrieben - angeblich auf Anregung heimischer Feinde ${ }^{50}$. Das Kapitel schließt mit einer Nachricht über Oldřichs Heirat mit Krzesinas Gattin Božena und die Geburt ihres Sohnes Břetislav. Alles erneut ohne Datum ${ }^{51}$. Ein ausnahmsweise längerer Abstecher in die römisch-deutsche Geschichte erwähnt den Tod Ottos III. und die Thronbesteigung Heinrichs (II.) sowie die Gründung des Bistums Bamberg. Vor allem beschreibt er jedoch die Begebenheit eines Einsiedlers und Jerusalempilgers, der unweit von Bamberg lebte und dem auf seiner Pilgerreise „durch ein Wunder“ Heinrichs

41 Ebd., S. 54 f. (I 30).

42 Ebd., S. 55 (I 30).

43 Ebd., S. 55 f. (I 31).

44 Ebd., S. 56 (I 31). Vgl. auch hier unten.

${ }^{45}$ Ebd., S. 57-60 (I 32-33).

46 Ebd., S. 60 (I 34).

47 Ebd., S. 60 (I 34).

48 Ebd., S. 60-63 (I 34).

49 Ebd., S. 63 f. (I 35). Zur Genealogie der Přemysliden um die Wende des 10. und 11. Jahrhunderts vgl. Josef ŽEMLIČKA, Přmyslovci: jak žili, vládli, umírali. Praha 2005, S. 37.

50 Die Chronik der Böhmen, S. 64 f. (I 36).

51 Ebd., S. 65 (I 36). Zur Datierung dieser Ergebnisse vgl. ŽEMLIČKA, Přemyslovci, S. 149-163. 
Tod mitgeteilt werden sollte ${ }^{52}$. Mit einem einzigen Satz wird unter dem Jahr 1003 die Massakrierung der Vršovci vermerkt ${ }^{53}$.

In das Jahr 1004 legte Cosmas eine Schilderung, eigentlich eine ganze Legende, über den Tod der Fünf Einsiedlerbrüder in Polen am 11. November ${ }^{54}$. Für das Jahr 1006 folgt ein Bericht über den Tod der Fürstin Hemma mit einer fiktiven Grabinschrift ${ }^{55}$, dann erst nach zehn leeren Jahreszahlen unter dem Jahr 1017 die Meldung über den Tod von Bischof Thiddag mit einem kurzen Nekrolog und der Feststellung, dass 1018 das Amt nach ihm von Bischof Ekkehard angetreten wurde ${ }^{56}$. Nach zwei „leeren“ Daten - 1019 und 1020 - setzt Cosmas fort mit einer lebhaften Beschreibung der Entführung von Judith, der Tochter des Herzogs von Schwaben Otto III. des Weißen, im Jahr 1021 aus dem Schweinfurter Kloster durch Oldřichs unehelichen Sohn Břetislav ${ }^{57}$. In dieser Darstellung ersetzte Cosmas die fehlenden konkreten Angaben durch seine rhetorische Kunst. Unter dem Jahr 1022 erscheint nur eine knapp gefasste Nachricht über die Christenverfolgungen in Polen ${ }^{58}$. Der folgende Bericht über den Tod von Bischof Ekkehard am 8. August 1023 wird wieder mit einem Nekrolog und der Erwähnung von Ekkehards Verdiensten um die Festlegung der Höhe des Kirchenzehnten in Böhmen vervollständigt ${ }^{59}$. Das Kapitel endet mit einer kurzen Feststellung über die Weihe von Bischof Hizzo am 29. Dezember des gleichen Jahres ${ }^{60}$. Kurze annalistische Einträge informieren über den Tod König Heinrichs 1024 und von Bolesław den Tapferen von Polen 1026 ${ }^{61}$, und nach einigen leeren Zeilen mit Jahreszahlen folgt ein Bericht über Břetislavs Sieg über die Ungarn 1030 und die Plünderung ihres Landes. ${ }^{62}$ Die nächste Nachricht, über den Tod von Bischof Hizzo am 30. Januar 1030, ist wieder mit einem Nekrolog versehen, in dem das Aussehen des Kirchenfürsten erwähnt und vor allem seine charitative Tätigkeit betont wird ${ }^{63}$. Mit leichter Ironie informiert der Verfasser über den Antritt des sechsten Prager Bischofs Severus und den Gründen für seine Beförderung - es geht um Severus' bekannte kulinarische Künste ${ }^{64}$. Nach annalistischen Einträgen über die Weihe von Bischof Severus 1031 und nach einigen leeren Jahreszahlen folgt ein Bericht über den Tod

52 Die Chronik der Böhmen, S. 65-68 (I 37). Vgl. Siegfried HIRSCH - Harry BRESSLAU, Jahrbücher des Deutschen Reiches unter Heinrich II. Bd. 3. Leipzig 1875, S. 367 f.

53 Die Chronik der Böhmen, S. 68 (I 37).

54 Die Chronik der Böhmen, S. 68-72 (I 38).

55 Ebd., S. 72 (I 39). Vgl. dazu Marie BLÁHOVÁ, Vier Epitaphe aus den böhmischen mittelalterlichen Chroniken und Annalen, in: Theo Kölzer - Franz-Albrecht Bornschlegel - Christian Friedl - Georg Vogeler (Hgg.), De litteris, manuscriptis, inscriptionibus.... Festschrift zum 65. Geburtstag von Walter Koch. Wien/Köln/Weimar 2007, S. 271-278.

56 Die Chronik der Böhmen, S. 72 (I 39).

57 Ebd., S. 73 ff. (I 40). Zu diesem Ereignis vgl. Barbara KRZEMIEŃSKA, Břetislav I.: Čechy a střední Evropa v prvé polovině 11. století. Praha 1999, S. 88-129; ŽEMLIČKA, Přemyslovci, S. 64 f., 108 f.; Marie BLÁHOVÂ, Přemyslovci mezi Západem a Východem: dynastické vztahy českých knížat a prvních králů a jejich politické souvislosti (do konce 12. století), in: Tomasz Ciesielski - Wojciech Iwańczak u. a. (Hgg.), Czechy i Polska między Wschodem i Zachodem - średniowiecze i wczesna epoka nowożytna (Materialy międzynarodowej konferencji naukowej). Warszawa 2016, S. 17-38.

58 Die Chronik der Böhmen, S. 75 (I 40).

59 Ebd., S. 75 f. (I 40).

60 Ebd., S. 76 (I 40).

61 Ebd., S. 76 (I 41).

62 Ebd., S. 76 (I 41).

${ }^{63}$ Ebd., S. 76 (I 41).

${ }^{64}$ Ebd., S. 76 f. (I 41 ). 
des Fürsten Boleslav III. 103765. Das nächste Kapitel wird mit einem Bericht über den Tod von Fürst Oldřich am 9. November des gleichen Jahres (1037) eingeleitet, wonach eine eingehende Schilderung über die Thronbesteigung von Oldřichs Sohn Břetislav mit fiktiven Reden von Břetislavs Onkel Jaromír folgt ${ }^{66}$. Mit dem Bericht von Jaromírs Tod am 4. November 1038 durch die Hand von Kochan aus dem Geschlecht der Vršovci, als Antwort auf Jaromírs Worte an die Adresse der Vršovci bei der Thronbesteigung des Fürsten Břetislav, endet das letzte Kapitel des ersten Buchs, und damit auch das ganze erste Buch der Cosmas-Chronik ${ }^{67}$.

Aus dem vorgelegten Überblick der Berichte im zweiten Teil des ersten Buchs der Chronik geht hervor, dass Cosmas Informationen und Schilderungen verschiedener Art zur Verfügung hatte. Genau datiert sind aus den Reichsannalen entnommene Berichte, in diesem Teil von Cosmas Chronik vor allem aus der Fortsetzung der Chronik Reginos von Prüm ${ }^{68}$ - der Bericht über den Feldzug des Reichskönigs gegen den rebellischen böhmischen Fürsten Boleslav, auch wenn er die tschechische Geschichte betrifft, gehört in diese Kategorie $^{69}$. Dann folgen regelmäßige Angaben zu Antritt und Tod der Prager Bischöfe, sowie Berichte über die Reihenfolge beziehungsweise den Antritt und Tod der böhmischen Fürsten. Die Berichte über den Tod der geistlichen, mitunter auch der politischen Laienpersönlichkeiten, sind gewöhnlich mit Nekrologen versehen, in denen regelmäßig deren „Tugenden“ - oder auch Untugenden, wie bei Boleslav I. - aufgezählt werden. Häufig sind dies jedoch lediglich rhetorische Klischees, nur ausnahmsweise erfuhr Cosmas aus seinen Quellen etwas über ihre tatsächlichen Taten. $\mathrm{Zu}$ diesen Berichten kommen noch einige kurze annalistische Vermerke aus der böhmischen Geschichte hinzu. An einigen Stellen fügte Cosmas eingehende Schilderungen ein, die zwar historische Fakten enthalten, ausnahmsweise auch mit Zeitangaben, doch gibt ihre Darstellung nicht immer die historische Realität wieder, sondern ist das Ergebnis von Cosmas rhetorischen Fähigkeiten, mit denen der Chronist offenbar den Mangel an Informationen ersetzt, beziehungsweise entspringen die Darstellungen Cosmas Phantasie. Diese Schilderungen sind eher ein Spiegelbild der mündlichen Tradition, die von Cosmas gehörig ausgeschmückt und erweitert wurde.

Eine weitere Quelle für Cosmas waren die Legenden. Der Prager Dekan verwies im von uns analysierten Teil seiner Chronik nur kurz auf die allgemein bekannten Vita des hl. Wenzel und die des hl. Adalbert, detailliert schildert er das Leben und die Leiden der Fünf Heiligen Brüder.

Was waren jedoch die Quellen für die konkreten datierten Berichte (außer den aus den Reichsannalen übernommenen Texten)? Als Quelle für Cosmas ist an erster Stelle der Katalog der Prager Bischöfe ${ }^{70} \mathrm{zu}$ identifizieren. Dieser wurde offenbar von Beginn des

65 Ebd., S. 77 (I 41).

66 Ebd., S. 77-79 (I 42).

67 Ebd., S. 79 f. (I 42).

68 Ebd., S. 40 f. (I 20); Continuatio Reginonis, hg. von Friedrich KURZE, in: Reginonis abbatis Prumiensis Chronicon cum continuatione Treverensi (MGH Scriptores rerum Germanicarum in usum scholarum separatim editi. Bd. 50). Hannover 1890, S. 159-177.

69 Die Chronik der Böhmen, S. 41 (I 20); vgl. Continuatio Reginonis, S. 164.

70 Vgl. dazu Marie BLÁHOVÁ, Stř̌edověké dějiny pražského biskupství jako pramen dějin církevní správy v Čechách, in: Emil Kordiovský - Libor Jan (Hgg.), Vývoj církevní správy na Moravě. Mikulov/Brno 2003, S. 77-90. Das älteste Beleg des Katalogs der Prager Bischöfe ist jedoch nicht die nicht erhaltene Bischofsgalerie in der Kapelle des Prager Bischofshofes, wohl aus den 30. Jahren des 14. Jahrhunderts 
Bistums an geführt. In dem Katalog erfasste man die Daten für Antritt und Weihe, ebenso das Todesdatum der Prager Bischöfe, mitunter auch ihre bedeutenden Taten. Dank dem Bischofskatalog konnte Cosmas die vollständige Reihe der Prager Bischöfe zumeist auch mit den genauen Daten ihres Antritts auf den Bischofsstuhl beziehungsweise ihrer Weihe oder Inthronisation, respektive auch der Investitur angeben, bei einigen auch bedeutsame Taten oder Ereignisse aus ihrer Amtszeit.

Bei den Berichten über den Amtsantritt der Bischöfe führt Cosmas gewöhnlich Angaben zu den Umständen und Voraussetzungen ihrer Wahl oder Auswahl sowie über ihre Qualifikation für das Amt beziehungsweise über ihre Weihe und Thronbesteigung an.

Der Sachse Thietmar, ein Mann von bewundernswerter Redegewandtheit und Gelehrtheit, kam einst nach Prag zur Wallfahrt, machte sich mit dem Fürsten Boleslav II. bekannt, erlangte dessen Vorliebe und Freundschaft. Da er die slawische Sprache vollkommen beherrschte, berief Boleslav, als er den Bischofsstuhl besetzen wollte, ihn nach Böhmen und erreichte bei den führenden Männern des Landes und beim Volk, dass sie ihn zum Bischof wählten ${ }^{71}$. Der Fürst sandte ihn dann zu Kaiser Otto mit dem Ersuchen um seine Weihe. Der Slavnikide Adalbert kehrte kurz vor Thietmars Tod von den Schulen nach Böhmen zurück, vollzog aufopferungsvoll die Begräbniszeremonien, weilte oft im Gebet, erteilte Almosen, was den Fürsten und die Großen des Landes dazu führte, ihn als Bischof auszuwählen ${ }^{72}$. Nach Adalberts Tod wandte sich Boleslav II. an den Kaiser mit der Bitte, ihm einen Bischof zu senden, denn in Böhmen gab es damals niemanden für dieses Amt Geeigneten. Otto wählte seinen Kaplan Thiddag aus ${ }^{73}$. Über Bischof Ekkehard führt Cosmas bei dessen Amtsantritt keinerlei Einzelheiten an ${ }^{74}$. Ebenso wie er zu Hizzo lediglich konstatiert, dass er am 29. Dezember 1023 vom Mainzer Erzbischof geweiht wurde ${ }^{75}$.

Widerspruchsvolle Angaben macht Cosmas über Strachkvas, der Adalbert im Bischofsamt ersetzen sollte, jedoch während der Bischofsweihe starb. Strachkvas wurde als „hervorragendes Kind der ausgezeichneten Ehefrau“ von Boleslav I. geboren. Der Vater versprach ihn Gott zur Aussöhnung mit ihm für den Mord am heiligen Wenzel ${ }^{76}$. In einem fiktiven Gespräch, in dem Bischof Adalbert sich bemüht haben soll, ihn zu überreden, das Bischofsamt anzunehmen, eignete er sich mit „seiner Gelehrtheit und dem Sakrament seines Amtes“ gut für das Bischofsamt ${ }^{77}$. Strachkvas lehnte das Amt damals resolut ab. Als jedoch Adalbert aus Böhmen wegging und es ablehnte zurückzukehren, „entbrannte Strachkvas in aufgeblasenem Stolz für die Bischofswürde“, er soll ein schlechter Mensch gewesen sein, „in seiner Bekleidung eitel, in seinem Denken aufge-

(vgl. Chronicon Francisci Pragensis [Fontes rerum Bohemicarum, Series nova 1], hg. von Jana ZACHOVÁ. Praha 1997, S. 44 [I 16]), sondern der Bischofskatalog in der Handschrift der komputistischen Texte aus dem dritten Viertel des 13. Jahrhunderts (vor 1278) Clm 17703, fol. 89v. Vgl. Catalogus codicum latinorum Bibliothecae Regiae Monacensis. Bd. 2. Teil 3, hg. von Carolus HALM - Fridericus KEINZ - Gulielmus MAYER - Georgius THOMAS. München 1878 (unveränderter Nachdruck 1969), S. 117.

71 Die Chronik der Böhmen, S. 44 f. (I 23).

72 Ebd., S. 46 f. (I 25).

73 Ebd., S. 55 f. (I 31). Vgl. auch hier unten.

74 Ebd., S. 72 (I 39).

75 Ebd., S. 76 (I 40).

76 Ebd., S. 36 (I 17).

77 Ebd., S. 52 (I 29). 
blasen, in seinen Taten zerstreut, in den Augen unstet, in der Rede leer, in den Sitten ein Heuchler und ein Hirt in vielerlei Irrglauben und in allen bösen Taten ein Erzpriester der Unedlen"78.

In den Nekrologen, die regelmäßig in die Berichte über den Tod der Bischöfe aufgenommen wurden, werden eher ausnahmsweise einige ihrer Taten erwähnt. Regelmäßig führt Cosmas jedoch die Charakteristik der Person sowie die Tugenden des Bischofs an. Ausnahmslos sind dies Angaben, die der Bischofskatalog enthalten konnte.

Die Charakteristika und Tugenden der Bischöfe in den Nekrologen formulierte Cosmas in der Regel nur allgemein und schrieb den Bischöfen zumeist die üblichen Bischofstugenden zu. Thietmar weihte die uneingeweihten Kirchen und taufte ungetaufte Einwohner. Dann „gab er die ihm anvertrauten Pfunde hundertfach an Christi zurück“79, detaillierter schreibt Cosmas über die Ereignisse aus dem Leben des Slavnikiden Adalbert, die er jedoch aus Legenden entnahm. Erst über Bischof Severus bringt Cosmas eingehendere Kunde aus dessen Amtszeit. Cosmas macht also, mit Ausnahme von Adalbert, über die Bischöfe des letzten Drittels des 10. Jahrhunderts und des ersten Viertels des 11. Jahrhunderts durchweg Angaben, die der Bischofskatalog, eventuell die Traditionen des Prager Bischofskapitels enthielten. Thiddag war ein würdiger Nachfolger des heiligen Adalberts, körperlich war er keusch, in den Sitten golden, in den Taten strahlend... ${ }^{80}$ Ekkehard war den Mächtigen gegenüber unnachgiebig, zu den Niedrigen und Stillen freundlich und bescheiden, ein redegewandter Prediger und freigiebiger Almosengeber. Hier kommen jedoch bereits auch konkrete Informationen - er erhöhte den Kirchenzehnt, so dass jeder, ob mächtig oder reich oder arm, wer zumindest ein Feldgut als Lehen oder Eigentum besaß, dem Bischof zwei Scheffel zu zahlen hatte, fünf Handbreit und

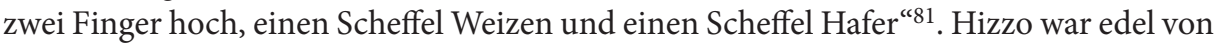
Geburt, noch edler in seinem Verhalten, er besuchte oft die Kerker und Krankenhäuser, hatte stets Überblick über die Einwohner, täglich verköstigte er vierzig Arme. Hier erwähnt Cosmas auch sein Aussehen: er soll ein Mann von ungewöhnlich schöner Gestalt mit weißem Haar gewesen sein ${ }^{82}$. Konkrete Berichte, auch wenn es fraglich ist, inwieweit sie der Wahrheit entsprachen, erstattet Cosmas über Severus ${ }^{83}$. Besonders ausführlich beschrieben ist dessen Teilnahme an der Überführung (genauer gesagt am Raub) der sterblichen Überreste des heiligen Adalberts von Gniezno nach Prag, womit auch das Erlassen von Gesetzen zusammenhing, was jedoch bereits Gegenstand des zweiten Buchs der Cosmas-Chronik ist ${ }^{84}$.

Eine Analyse der Charakteristiken der Prager Bischöfe zeigt, dass Cosmas zu diesem Thema offensichtlich keine anderen schriftlichen Quelle zur Verfügung hatte als den Bischofskatalog. Dieser gab die Hauptdaten zum Bischofsamt an, offenbar auch die Gründe der „Wahl“, mitunter auch „Verdienste“ der einzelnen Bischöfe oder Bemerkenswertes über sie. Seine zweite Quelle war wohl die Tradition des Bischofskapitels. Dies wird angedeutet zum Beispiel durch die Charakteristika des Bischofs Hizzo. Da Cosmas keine

78 Ebd., S. 55 (I 30).

79 Ebd., S. 46 (I 24).

80 Ebd., S. 72 (I 39).

81 Ebd., S. 75 f. (I 40).

82 Ebd., S. 76 (I 41).

83 Ebd., S. 76 f. (I 41).

84 Ebd., S. 85-89 (II 4). 
andere Quelle hatte, erwähnte er auch nicht die Teilnahme der Prager Bischöfe an den Reichssynoden und ihr eventuelles Engagement in Angelegenheiten der Reichskirche ${ }^{85}$, ebenso wie andere Ereignisse aus ihrer Amtszeit.

Etwas komplizierter ist die Frage der Reihenfolge und Datierung der Regierung der böhmischen Herrscher. Diese werden regelmäßig ab Bořivoj (mit dem erwähnten fiktiven Taufdatum 894) angegeben, bis zur Thronbesteigung Boleslavs III. im Jahr 999. Über das Ende des 10. Jahrhunderts besitzt Cosmas jedoch etwas verwirrte Informationen, er gibt Boleslavs Brüder als seine Söhne aus, Bolesław den Tapferen gibt er als Mieszko aus. Den Polen Wladiwoj, den Bolesław der Tapfere auf den böhmischen Thron einsetzte, erwähnt er überhaupt nicht. Oldřich (1012-1033, 1034-1035) nennt er bereits 1002 auf dem böhmischen Thron, Jaromír (Anfang 1003, dann 1004-1012, schließlich kurz 1034, 1035) vernachlässigt er als Herrscher vollständig. Bei den ältesten Herrschern, bis zum heiligen Wenzel, sind allerdings in der Chronik keine Regierungszeiten angegeben. Das Todesdatum des heiligen Wenzel 28. September 929 ist offenbar falsch ${ }^{86}$. Bei Boleslav I. ist das Todesjahr angeführt, jedoch ohne Tagesangabe. Boleslav II. ist der erste Herrscher, bei dem Cosmas die Regierungsdauer angibt und einen Nekrolog hinzufügt ${ }^{87}$, allerdings wieder ohne Todesdatum. Boleslav III. trat "nach des Vaters Tod“ an, wiederum ohne konkretes Datum ${ }^{88}$. Zumindest mit dem Jahr datiert werden Rückkehr und Regierungsbeginn von Fürst Oldřich (Cosmas zufolge 1002) ${ }^{89}$, der Tod von Fürstin Hemma 1006 ${ }^{90}$, Judiths Entführung $1022^{91}$. Erst der Tod des Fürsten Oldřich (9. November 1037) ${ }^{92}$ und seines Bruders Jaromír (4. November 1038) ${ }^{93}$ sind auch mit Tagesangabe datiert. Břetislavs Sohn Spytihněv ist nach Strachkvas ein weiterer Přemyslide, bei dem Cosmas zumindest das Geburtsjahr angab $(1031)^{94}$.

Die Angaben zu den böhmischen Fürsten sind noch weniger exakt als jene über die Prager Bischöfe. Cosmas besaß offenbar über sie nicht so genaue Nachrichten, wie sie im Bischofskatalog beziehungsweise in den Traditionen der Prager Kirche über die Bischöfe zu finden waren. Für die ältere Zeit gibt Cosmas eine Aufzählung der Herrscher ohne Einzelheiten an, die Informationen über den heiligen Wenzel und teilweise auch Boleslav I. entnahm er aus den Legenden, weitere erfassten wohl die Traditionen (Bau der Befestigung von Stará Boleslav, Judiths Entführung usw.). Wahrscheinlich standen

85 Das Reichsengagement ist bei Bischof Hizzo (Codex diplomaticus et epistolarius Regni Bohemiae. Bd. 1, hg. von Gustav FRIEDRICH. Praha 1907, Nr. 45, S. 49 f.) und vielleicht auch bei Severus. Vgl. Heinrici III. et Leonis IX. Concilium Moguntinum, in: MGH Constitutiones et acta publica imperatorum et regum. Bd. 1: 911-1197, hg. von Ludwig WEILAND. Hannover 1893, S. 99, Anm. i: „Albertus Spragensis episcopus“, was als „s. Adalberti S. Pragensis episcopus“, also Severus, zu interpretieren ist. Vgl. Tomasz JUREK, Los arcybiskupstwa Gnieźnieńskiego w XI wieku, in: Jerzy Strzelczyk - Janusz E. Górny (Hgg.), 1000 lat Archidiecezji Gnieźnieńskiej. Gniezno 2000, S. 52 f.; David KALHOUS, Jak viděla Hnězdno roku 1000 středověká tradice?, in: Martin Wihoda - Lukáš Reitinger (Hgg.), Proměna středovýchodní Evropy raného a vrcholného středověku. Brno 2010, S. $352 \mathrm{f}$.

$86 \mathrm{Vgl}$. Zdeněk FIALA, Dva kritické příspěvky ke starým dějinám českým, I. O datu smrti knížete Václava I., in: Sborník historický 9 (1962), S. 6-40; Dušan TŘEŠTíK, Počátky Přemyslovců, S. 249-260.

87 Die Chronik der Böhmen, S. 57 (I 33).

88 Ebd., S. 57 (I 32), S. 60 (I 34).

89 Ebd., S. 64 (I 36).

90 Ebd., S. 72 (I 39).

91 Ebd., S. 75 (I 40).

92 Ebd., S. 77 (I 42).

93 Ebd., S. 79 (I 42).

94 Ebd., S. 77 (I 41). 
ihm auch nicht näher bekannte Einträge am ehesten wohl aus der Umgebung des Prager Domkapitels zur Verfügung. Für die Zeit der politischen und militärischen Wirren zur Wende des 10. und 11. Jahrhunderts erfasste er jedoch keine der erforderlichen Angaben, was bewirkte, dass Cosmas eine unrichtige Reihenfolge, falsche Daten und Verwandtschaftsbeziehungen der böhmischen Herrscher und auch den falschen Namen des polnischen Eroberers angab (Mieszko anstatt Bolesławs des Tapferen). Vielleicht hinderte die Prager Kanoniker auch die politische Lage in Böhmen an der Führung von historischen Einträgen, und später kamen sie nicht dazu, den Mangel zu beheben, oder sie hatten nicht den Bedarf, dies zu tun. Cosmas kannte wahrscheinlich nicht den offiziellen Katalog der böhmischen Herrscher, der am Fürstenhof geführt wurde. Dieser Katalog beinhaltet mindestens die Reihenfolge der böhmischen Herrscher von Přemysl dem Pflüger an, wenn auch ohne Daten, einschließlich des Fürsten Wladiwoj, den Cosmas überhaupt nicht erwähnt ${ }^{95}$.

Es bleiben einige annalistische Einträge tschechischer Herkunft: der Tod des Großen Vok 968, der Tod Slavníks 981 (hier ist jedoch dem Eintrag ein umfangreicher Nekrolog beigefügt), der Tod Střezislavas, der Mutter des heiligen Adalberts, 989, der Eintritt des Bischofs Adalbert in das Kloster in Rom 990, die Ausrottung der Vršovci 1003, Břetislavs Feldzug nach Ungarn und die Niederlage der Ungarn 1030, der Tod Boleslavs III. 1037. Diese Berichte waren weder Bestandteil des höfischen noch des bischöflichen Katalogs. Ihre Vorlage waren wiederum am ehesten annalistische Einträge, die bei der Prager Kirche geführt wurden. Da die Todesberichte nur mit Jahreszahlen ohne Tagesdaten angegeben sind, konnten sie nicht aus den Nekrologien, beziehungsweise Obituarien gezogen werden ${ }^{96}$.

Insgesamt jedoch waren Cosmas Berichte, außer der vollständigen Reihe der Bischöfe, nur bruchstückhaft, zu zahlreichen Jahreszahlen gelang es ihm nicht, Berichte und Ereignisse zu finden, anderswo sind die Informationen zusammenhangslos und nicht ausgeglichen, sowohl hinsichtlich ihrer Wichtigkeit als auch was den Umfang der Schilderung betrifft.

Welchen Charakter besaßen also in diesem Kontext Cosmas Berichte über Bischof Thiddag? Cosmas erwähnt den dritten Prager Bischof erstmals in Zusammenhang damit, dass Fürst Boleslav II. nach dem Tod von Bischof Adalbert in Böhmen keinen geeigneten Kandidaten für den neuen Bischof fand, und in Befürchtung, dass die unlängst getauften Böhmen „zu den irrigen Ritualen und Lastern“ zurückkehren könnten, ersuchte er Kaiser Otto III. um einen Bischof ${ }^{97}$. Der Kaiser überlegte sorgfältig, welchen Geistlichen er für dieses Amt auswählen soll. Zufällig war am Hof sein Kaplan Thiddag anwesend, der aus Sachsen stammte und wohl ausgestattet war mit den erforderlichen sittlichen Eigenschaften und einer außerordentlichen Bildung, einschließlich der perfekten Kenntnis des

95 Die älteste Fassung des offiziellen Herrscherkatalogs ist im Kodex der Bibliothek des Prager Domkapitels G 5 im Epilog der Zweiten Fortsetzung der Cosmas' Chronik beinhaltet (Fontes rerum bohemicarum. Bd. 2, hg. von Josef EMLER. Praha 1874, S. 369 f.). Zum böhmischen Herrscherkatalog und seinen Redaktionen vgl. Marie BLÁHOVÁ, Středověké katalogy českých knížat a králů a jejich pramenná hodnota, in: Średniowiecze polskie i powszechne. Bd. 1. Katowice 1999, S. 33-63.

96 Obituarien als Cosmas Quelle der Todesdaten von Bischöfen und Fürsten nimmt irrig WOLVERTON, Cosmas of Prague, S. 57 f., Anm. 53, an. Zu den Nekrologien und Obituarien vgl. Nicolas HUYGHEBAERT, Les documents nécrologiques. Turnhaut 1972, S. 33-37.

${ }^{97}$ Die Chronik der Böhmen, S. 56 (I 31). 
Slawischen ${ }^{98}$. Diesen wählten also der kaiserliche Rat und der Kaiser, „große Freude verspürend" und erhoben ihn zum Prager Bischof und sandten ihn zum Mainzer Erzbischof, damit er ihn weihen möge. Dieser Darstellung zufolge war Thiddag der einzige Prager Bischof, der vom Kaiser und seinem Rat „gewählt“ wurde, und nicht vom böhmischen Fürsten und den Großen des Landes.

Am 7. Juli 998 wurde dann Thiddag geweiht und von der Priesterschaft und dem Volk der Prager Kirche empfangen und mit großer Freude auf den Bischofsthron an der Ecke des Altars von Sankt Veit gesetzt. Der Fürst war angeblich hoch erfreut, dass ein guter Hirte seine Herde anlächelte, und die Herde begrüßte mit Freuden den neuen Hirten ${ }^{99}$.

Trotz des verhältnismäßig langen Zeitraums von Thiddags Bischofsamt hält Cosmas weitere Berichte über Thiddag erst anlässlich seines Todes am 11. Juni 1017 bereit $^{100}$. Dabei konstatierte er zu ihn, wie schon teilweise bemerkt wurde, dass er ein würdiger Nachfolger des heiligen Adalberts war, körperlich war er keusch, in den Sitten golden, in den Taten strahlend, den Spuren seines Vorgängers folgend und die Schandtaten des ihm anvertrauten Volkes verfolgend, und wenn nicht mit dem Körper, so zumindest mit dem Geist erfuhr er das Martyrium. Er starb angeblich nicht nach der Sitte anderer Menschen, sondern dem Herrn folgend starb er in Frieden, und so schläft und ruht er auch.

Aus Thiddags Charakteristik geht hervor, dass Cosmas nicht viel über den dritten Prager Bischof wusste, so dass er sich mit den üblichen rhetorischen Topoi aushalf, mit denen man fast jeden Bischof charakterisieren konnte. Cosmas berichtete nichts über Taten oder Ereignisse aus Thiddags Amtszeit. In der Chronik wird auch nicht seine Teilnahme bei der Gründung eines der ältesten Klöster in Böhmen erwähnt, dem Kloster Insula auf einer Moldauinsel bei Davle, als Thiddag im Beisein des Gründersohns, des Fürsten Boleslav III., den Abt des gerade gegründeten Klosters Landbert weihte, wovon die Memorialnotizen des Klosters zeugen ${ }^{101}$. Cosmas wusste jedoch auch nichts darüber, dass Thiddag den von einem Schlaganfall betroffenen Fürsten behandelte ${ }^{102}$. Ebenso wusste er nicht von den Streitigkeiten mit dem Nachfolger Boleslavs II., Boleslav III. Nichts wusste er darüber, wie Thiddag mehrmals aus Böhmen verjagt wurde und sich nach Meißen flüchtete, von wo er regelmäßig unter dem Schutz Meißener Truppen zurückkehrte $^{103}$. Und überhaupt nicht erwähnte er die Neigung des Prager Bischofs zu Alkohol und dessen unmäßigem Konsum, der ihn mitunter auch an der Ausübung seines Amtes

\footnotetext{
98 „Forte aderat in regali curia capellanus nomine Thegdagus, actibus probis et moribus decoratus, liberalibus studiis adprime eruditus, genere de Saxonia, lingua perfecte imbutus Sclavonica." Ebd., S. 56 (I 31).

${ }^{99}$ Ebd., S. 56 (I 31).

${ }^{100}$ Ebd., S. 72 (I 39).

${ }^{101}$ Vgl. Codex diplomaticus et epistolarius Regni Bohemiae. Bd. 1, Nr. 40, S. 46 f., Ebd. Bd. 2, Nr. 359, S. 380 f. Zur Überlieferung dieser Memorialnotiz vgl. Rostislav NOVÝ, Diplomatické poznámky $\mathrm{k}$ donačním listinám českých klášterů a kapitul do konce 12. století, in: Studia mediaevalia Pragensia 2 (1991), S. 130 (mit der Literatur). Vgl. auch Jan BISTŘICKÝ, Über Falsifikate böhmischer Gründungsurkunden bis zum Ende des 12. Jahrhunderts, in: Archiv Mitteilungen 4 (1991), S. 186; Marie BLÂHOVÁ, Historická pamět v pramenech raně přemyslovských Čech, in: Jan Klápště - Eva Plešková - Josef Žemlička (Hgg.), Dějiny ve věku nejistot: sborník k př́ležitosti 70. narozenin Dušana Třeštíka. Praha 2003, S. 58.

102 Thietmari Merseburgensis episcopi Chronicon (MGH Scriptores rerum Germanicarum. Nova series. Bd. 9), hg. von Robert HOLTZMANN. Berlin 1935, S. 468 (VII 56). Vgl. dazu Václav NOVOTNÝ, České dějiny. Bd. 1. Teil 1: Od nejstarších dob do smrti knížete Oldřicha. Praha 1912, S. 447.

103 Thietmari Chronicon, S. 469 (VII 56). Vgl. NOVOTNÝ, České dějiny. Bd. 1/1, S. 667 f.
} 
hinderte (nicht befassen werde ich mich hier mit der Frage, ob seine Unfähigkeit, wegen zu starkem Händezittern Messen zu lesen, eine Folge des exzessiven Trinkens war oder eine Folge einer Krankheit, die er sich durch unmäßigen Alkoholkonsum zu "heilen“ bemühte) ${ }^{104}$. Diese Angaben fehlten im Bischofskatalog und Cosmas besaß keine andere Quelle und suchte auch nicht nach ihr.

\section{Danksagungen}

Diese Studie ist im Rahmen des Universitätsprogramms PROGRES Q 09: Geschichte der Schlüssel zum Verständnis der globalisierten Welt erschienen.

\section{LITERATURVERZEICHNIS}

\section{Quellen}

Catalogus codicum latinorum Bibliothecae Regiae Monacensis. Bd. 2. Teil 3, hg. von Carolus HALM - Fridericus KEINZ - Gulielmus MAYER - Georgius THOMAS. München 1878 (unveränderter Nachdruck 1969).

Chronicon Francisci Pragensis (Fontes rerum Bohemicarum, Series nova 1), hg. von Jana ZACHOVÁ. Praha 1997.

Codex diplomaticus et epistolarius Regni Bohemiae. Bd. 1, hg. von Gustav FRIEDRICH. Praha 1907.

Continuatio Reginonis, hg. von Friedrich KURZE, in: Reginonis abbatis Prumiensis Chronicon cum continuatione Treverensi (MGH Scriptores rerum Germanicarum in usum scholarum separatim editi. Bd. 50). Hannover 1890, S. 159-177.

Cosmae Pragensis Chronica Boemorum (MGH Scriptores Rerum Germanicarum. Nova series. Bd. 2), hg. von Bertold BRETHOLZ. Berlin 1923.

Fontes rerum bohemicarum. Bd. 2, hg. von Josef EMLER. Praha 1874.

Heinrici III. et Leonis IX. Concilium Moguntinum, in: MGH Constitutiones et acta publica imperatorum et regum. Bd. 1: 911-1197, hg. von Ludwig WEILAND. Hannover 1893, S. 97-100.

Merseburgensis episcopi Chronicon (MGH Scriptores rerum Germanicarum. Nova series. Bd. 9), hg. von Robert HOLTZMANN. Berlin 1935.

\section{Literatur}

Jan BISTŘICKÝ, Über Falsifikate böhmischer Gründungsurkunden bis zum Ende des 12. Jahrhunderts, in: Archiv Mitteilungen 4 (1991), S. 186-189.

Marie BLÁHOVÁ, Historická pamět v pramenech raně přemyslovských Čech, in: Jan Klápště - Eva Plešková - Josef Žemlička (Hgg.), Dějiny ve věku nejistot: sborník k př́ležitosti 70. narozenin Dušana Třštíka. Praha 2003, S. 53-69.

Marie BLÁHOVÁ, Přemyslovci mezi Západem a Východem: dynastické vztahy českých knížat a prvních králů a jejich politické souvislosti (do konce 12. století), in: Tomasz Ciesielski - Wojciech Iwańczak u. a. (Hgg.), Czechy i Polska między Wschodem i Zachodem - średniowiecze i wczesna epoka nowożytna (Materialy międzynarodowej konferencji naukowej). Warszawa 2016, S. 17-38.

Marie BLÁHOVÂ, Stř̌edověké dějiny pražského biskupství jako pramen dějin církevní správy v Čechách, in: Emil Kordiovský - Libor Jan (Hgg.), Vývoj církevní správy na Moravě. Mikulov/Brno 2003, S. 7790.

Marie BLÁHOVÁ, Středověké katalogy českých knížat a králů a jejich pramenná hodnota, in: Średniowiecze polskie i powszechne. Bd. 1. Katowice 1999, S. 33-63.

Marie BLÁHOVÁ, Vier Epitaphe aus den böhmischen mittelalterlichen Chroniken und Annalen, in: Theo Kölzer - Franz-Albrecht BornschlegeL - Christian Friedl - Georg Vogeler (Hgg.), De litteris,

104 Thietmari Chronicon, S. 469 f. (VII 56). Vgl. NOVOTNÝ, České dějiny. Bd. 1/1, S. 667. 
manuscriptis, inscriptionibus...: Festschrift zum 65. Geburtstag von Walter Koch. Wien/Köln/Weimar 2007, S. 271-278.

Zdeněk FIALA, Dva kritické příspěvky ke starým dějinám českým, I. O datu smrti knížete Václava I., in: Sborník historický 9 (1962), S. 6-40.

Siegfried HIRSCH - Harry BRESSLAU. Jahrbücher des Deutschen Reiches unter Heinrich II. Bd. 3. Leipzig 1875.

Ivan HLAVÁČEK, Die Formung der westslawischen Schrift-, Buch- und Bibliothekskultur unter dem Einfluß der lateinischen Kirche, in: Gli Slavi occidentali e meridionali nell' alto medioevo 30 (1983), S. 701-743.

Nicolas HUYGHEBAERT, Les documents nécrologiques. Turnhout 1972.

Tomasz JUREK, Losy arcybiskupstwa Gnieźnieńskiego w XI wieku, in: Jerzy Strzelczyk - Janusz E. Górny (Hgg.), 1000 lat Archidiecezji Gnieźnieńskiej. Gniezno 2000, S. 49-72.

David KALHOUS, Jak viděla Hnězdno roku 1000 středověká tradice?, in: Martin Wihoda - Lukáš Reitinger (Hgg.), Proměna středovýchodní Evropy raného a vrcholného středověku. Brno 2010, S. 339-358.

Antonín KOLÁR̆, Kosmovy vztahy k antice, in: Sborník filosofické fakulty University Komenského $v$ Bratislavě 3/28 (1925), S. 21-99.

Barbara KRZEMIEŃSKA, Břetislav I.: Čechy a střední Evropa v prvé polovině 11. století. Praha 1999.

Rosamond McKITTERICK, Entstehung und Gestaltung fränkischer Annalen im Spiegel der Lorscher Annalen, in: Richard Conradini - Max Diesenberger - Meta Niederkorn-Bruck (Hgg.), Zwischen Niederschrift und Wiederschrift: Hagiographie und Historiographie im Spannungsfeld von Kompendienüberlieferung und Editionstechnik. Wien 2010, S. 104-114.

Rostislav NOVÝ, Diplomatické poznámky k donačním listinám českých klášterů a kapitul do konce 12. století, in: Studia mediaevalia Pragensia 2 (1991), S. 125-146.

Georg SCHEIBELREITER, Der Tod Lamberts von Maastricht, in: Natalie Fryde - Dick Reitz (Hgg.), Bischofsmord im Mittelalter: Murder of Bishops. Göttingen 2003, S. 51-82.

Wesley M. STEVENS, Ars computi quomodo inventa est, in: Richard Conradini - Max Diesenberger Meta Niederkorn-Bruck (Hgg.), Zwischen Niederschrift und Wiederschrift: Hagiographie und Historiographie im Spannungsfeld von Kompendienüberlieferung und Editionstechnik. Wien 2010, S. 29-66.

Miloslav ŠVÁB, Latinské předkarlovské kroniky a listy Jindřicha z Isernie ve vztahu k antice, in: Ladislav Varcl (Hg.), Antika a česká kultura. Praha 1978, S. 34-41.

Dušan TŘEŠTÍK, Anfänge der böhmischen Geschichtsschreibung: die ältesten Prager Annalen, in: Studia Źródłoznawcze. Commentationes 23 (1978), S. 1-37.

Dušan TŘEŠTÍK, Kosmova kronika: studie $k$ počátkům českého dějepisectví a politického myšlení. Praha 1968.

Dušan TŘEŠTÍK, Počátky Přemyslovců: vstup Čechư do dějin (530-935). Praha 1997.

Lisa WOLVERTON, Cosmas of Prague: Narrative, Classicism, Politics. Washington D.C. 2015.

Josef ŽEMLIČKA, Přemyslovci: jak žili, vládli, umírali. Praha 2005. 